\section{Carnegie's misdiagnosis}

A new study of undergraduate education misses an opportunity to tell what is really wrong.

US ACADEMICS and their followers, in one of their periodic fits of introspection, have been giving pious attention to a report from the Carnegie Foundation for the Advancement of Teaching on the state of higher education and, in particular, to its judgement that, "driven by careerism and overshadowed by graduate and professional education, many of the nation's colleges and universities are more successful in credentialing ( $\mathrm{sic}$ ) than in providing a quality education for their students". There will be few who disagree with that, but the foundation's study, College - the undergraduate experience in America, by Mr Ernest Boyer, is most notable for what it has left unsaid.

Carnegie is, naturally, right to be troubled by the lack of individual attention given to undergraduates and to sympathize with them in the hard choice of a course of study. Then few will quarrel with Boyer's plea for better personal advice to students, especially during the difficult transition from high-school to college. And nobody will argue against the case for higher standards of literacy. But the argument hangs too much on the subjective experiences of undergraduates and teachers, as reported and, often touchingly, recorded. This preoccupation with tensions between "individual interests and shared concerns" means that some of the urgent questions about the future of higher education in the United States are mis-stated.

One is the pattern of the curriculum. US universities have always required less specialization than have universities elsewhere, and deserve credit for it. Their accessibility is unmatched anywhere in the world. But the worry now is that things have gone too far, and that US undergraduates have too much latitude to choose from a curriculum increasingly resembling a supermarket for credit courses, with students free to experiment as they please until the required number of credits is reached. The Carnegie report rightly raises this important issue, with which William J. Bennett, the US Secretary of Education, startled some of those at Harvard University's 350th birthday celebrations earlier this year, taking Harvard as his inappropriate example. Carnegie's remedy for the laundry-list approach to education is to call for a core curriculum. The need for some high-level coordination cannot be denied. But if Carnegie wishes to be taken seriously, it must devise a more persuasive core than the amalgam now put forward; an "integrated core" that would include language, art, history, institutions, nature ("the ecology of the planet"), work ("the value of vocation") and identity ("the search for meaning"). All this, but no general science course?

The Carnegie study also draws attention to the conflicts that can arise in research universities between the demands of teaching and of research. The story is familiar: because academic prowess is measured largely by published research papers, faculty members devote their best efforts to excellence in research, sometimes at the expense of teaching. Boyer's suggestion that research universities should establish a new rank of "distinguished teaching professor", extending status and salary incentives to outstanding teachers, might serve well in some colleges and universities, but ignores the frequency with which excellence in teaching and in research go together, hand in glove. In the end, the research universities will have to deal with this internal conflict internally, by requiring that faculty members are not so distracted by external interests and commitments as to impede their discharge of their academic responsibilities, to students as well as to research. This goal will not be easily won, but the research universities eager that their reputations should survive will give it more attention than has been the habit in recent years. The professorial status of good teachers is a palliative only.

The Carnegie Foundation would also have done education a greater service if it had tackled some of the problems of higher education that are beyond the control of the universities themselves. The most immediate threat is the accumulated effect of the dereliction of university research facilities and cutbacks in support for students. Many of the institutions that have served the United States well in the past, the less well-known universities that dominate the Boyer's survey in particular, are now ominously stretched. Government officials are fond of pointing out that support for basic research at universities has increased in recent years, which is true. But the increase followed a long decline during the 1970s that has not yet been made good. Decaying facilities and equipment are depressingly common on all but the most successful campuses. Federal support for university research facilities dropped from \$404 million in 1966 to a low point of just $\$ 37$ million in 1981 (1981 prices). Support for graduate students in the sciences has fallen by about a half since 1969. The efforts of the National Science Foundation to promote excellence in science education, all but abolished by President Reagan at the start of his first term of office, are improving, but slowly. Small wonder that the proportion of bachelor's degrees in physical and biological sciences has fallen since the late 1970 s, with even engineering starting to tail off in 1985. Yet fewer undergraduates now means fewer faculty members in ten years' time, less research and, probably, less teaching. Unless the federal government decides to act, these are the circumstances that will condition some future Carnegie report on the parlous condition of higher education in the United States at the end of the decade.

\section{Fire without smoke}

Two retracted papers do not make a scandal, but too much reticence about the circumstances may.

DANA-Farber Cancer Institute has a problem (see page 197). It has announced that two papers describing a T-cell activating substance called interleukin-4A are being retracted from the journals in which they were published. This is certainly not the first time that scientific papers have been withdrawn, and it will not be the last. It is very much to the credit of Dana-Farber that the retractions were issued as soon as the errors in the data were discovered.

Where Dana-Farber's problem lies is in the way it described - or more properly failed to describe - the reasons for the retraction. Obviously there are many reasons why papers may have to be retracted. Cell culture contamination, reagent impurities, inadvertent miscoding of results can all be discovered, long after the fact, even in the most careful and thorough laboratories. But Dana-Farber has not invoked any of these readily believable explanations, choosing to make the blunt statement that an investigation is under way, and that retraction letters have gone out. This approach can only leave a cloud of suspicion hanging over the institute. What sort of investigation is it that can immediately conclude that the data upon which a paper is based are incorrect and not reproducible without saying how that fact is known?

Unhappily, there have been all too many recent instances in which falsification of data has brought laboratories into trouble. By declining to comment about its investigation, Dana-Farber, perhaps unwittingly, merely encourages speculation. Officials at Dana-Farber will correctly say that it is unfair to make allegations that could have a profound influence on a scientist's career before they are completely investigated. But silence is not the answer. Surely it is possible to say what first aroused suspicions about the data without jeopardizing future investigation? Surely retractions with no explanation will focus interest on the case longer than a simple statement about the circumstances as they are at present known? The scientific community should be credited with the good sense to understand the distinction between an investigation and a final judgement. 